\title{
Rapid Sex-typing of Asparagus for Male Hybrid Seed Production using $n$-Propyl $N$-(3,4-dichlorophenyl)carbamate (NPC)
}

\section{Aneja, T.J. Gianfagna, S.A. Garrison, and E.F. Durner \\ Plant Science Department, Rutgers University, 59DudleyRoad, New Brunswick, NJ $08901-8520$ \\ Additional index words. flowering, germination, $N$-phenylcarbamate, Asparagus officinalis}

\begin{abstract}
Precocious flowering can be induced in asparagus (Asparagus officinalis L.) seedlings with $N$-phenylcarbamate herbicides, such as $n$-propyl $N$-(3,4-dichlorophenyl) carbamate (NPC); however, only $\approx \mathbf{5 0 \%}$ of the treated seeds produce flowering plants because these compounds inhibit germination and seedling emergence. We have improved the treatment method by determining the environmental conditions, timing, dose, and duration needed to maximize the percentage of germination, emergence, and flowering. Imbibing seeds in water for 5 days, and then treating germinated seeds with 0.4 mM NPC for 5 days after radicle emergence, with seedling aeration in the light, resulted in the production of flowering seedlings from $>90 \%$ of the treated seeds. For freshly harvested seeds, in which germination rates are more variable than aged seeds, individual seedlings must be transferred to NPC within 1 day after radicle emergence to produce a high percentage of flowering plants. For seven male asparagus cultivars, chemical induction of flowering in seedlings with NPC produced a sex ratio similar to that of field-grown plants, demonstrating that NPC induces flowering without altering floral differentiation or sex expression. This method can be used for rapidly and accurately identifying the percentage of females in "male" cultivars.
\end{abstract}

Asparagus is dioecious. While there is only one type of female $(\mathrm{XX})$, there are two types of males, a normal heterozygous male (XY) and a homozygous male or "supermale" (YY). A cross between a female and an XY male will produce equal numbers of $\mathrm{XY}$ males and females, whereas a cross between a YY supermale and a female will produce exclusively XY males. The supermales are usually obtained from the occasional development and fertilization of a functional female flower on XY male plants that results in viable seed set. Supermales can also be generated from anther or pollen culture (Feng and Wolyn, 1994). The supermales are usually low in vigor and not suitable for cultivation, but are valuable in plant breeding.

Male cultivars of asparagus are considered to be superior to dioecious cultivars in crop yield because males do not divert photosynthate into seed production and do not produce seedlings that compete with established plants for water and nutrients. In a comparison at three locations, yields of six male hybrids were significantly greater than, and often double that, of the dioecious 'Mary Washington' (Ellison et al., 1990). In an evaluation of 14 dioecious hybrids, 3-year-old male plants produced more spears than their female counterparts in 10 of the hybrids (GonzalezCastanon, 1990).

Received for publication 10 Aug. 1998. Accepted for publication $18 \mathrm{Feb} .1999$. The cost of publishing this paper was defrayed in part by the payment of page charges. Under postal regulations, this paper therefore must be hereby marked advertisement solely to indicate this fact.
Asparagus seed can be sold as all male only if it meets standards for seed purity as measured by the percentage of contaminating female seeds $(<5 \%)$ in the seed lot. Seed production problems occur if pollen from XY males outside the seed field is transferred to female seed parents, or if seedling XY males become established within the seed field from dropped fruit, where they can become a source of XY pollen. As a result, all seed lots must be tested and the sex ratio determined and clearly indicated. Since asparagus usually requires 6 to 15 months from seed to flower, methods to induce early flowering would enable rapid testing of seed lots for the presence of contaminating females. Currently, seed is planted in the greenhouse soon after harvest, and, after several months, seedlings are transplanted to the field in spring. Plants must be continuously monitored during the summer, as most plants will produce only a few flowers during a brief period. Plants that do not flower are transplanted to containers and returned to the greenhouse; this is important because the late flowering group usually contains a higher percentage of female plants (J.H. Ellison, unpublished data). Since up to 12 to 15 months are required to determine the sex ratio, seed is usually stored for 1 year before it can be sold.

Precocious flowering of asparagus, in as little as 3 to 4 weeks from sowing, can be induced by treatment with the $s$-triazine, phenylurea, and $\mathrm{N}$-phenylcarbamate classes of herbicides (Abe and Kamiya, 1986; Abe et al., 1987, 1990; Yanosaka et al., 1989). Only the apical meristem of the first shoot is sensitive to induction, and treatment must occur during germination. The flowering seedlings produce a shoot with a terminal flower (Fig. 1C). Additional shoots develop from the newly forming crown, but these are vegetative and insensitive to treatment. Unfortunately, the chemicals that induce flowering also inhibit germination and seedling emergence. Only $20 \%$ to $30 \%$ of the seeds treated with atrazine [2-chloro-4-(ethylamino)-6-(isopropylamino)$s$-triazine] or diuron [3-(3,4-dichlorophenyl)1,1-dimethylurea] will develop into flowering seedlings. The $N$-phenylcarbamates are less toxic and will induce $\approx 50 \%$ flowering. Other related compounds [ $N$-phenylalkanamides, $N$ alkylbenzamides (Hara et al., 1992), $N$-phenyl- $N^{\prime}$-alkoxyformamidines (Kusukawa et al., 1994), and thiocarbamates (Yeo et al., 1996)] are reported to induce an even greater percentage of plants to flower.

The percentage of treated seeds that develop into flowering seedlings is the product of the percentages of seed germination, seedling emergence, and emerged plants that flower. For accurate sex determination, each of these percentages must be maximized since a sex-type bias may exist for any of these factors, as well as for response to chemical treatment itself.

In this paper we report the results of experiments with a commercially available $N$-phenylcarbamate, [ $n$-propyl $N$ - $(3,4$ dichlorophenyl)carbamate] or NPC, one of the most potent flower-inducing derivatives in this class of compounds. Our objectives were to: 1) optimize the environmental conditions and treatment methodologies to maximize the flowering percentage, 2) determine if the sex ratio obtained by chemical induction was statistically the same as the ratio observed in field-grown plants, and 3) use and assess the methods developed to sex-type a freshly harvested seed lot that could then be used for spring sales.

\section{Materials and Methods}

The NPC was obtained from the SigmaAldrich library of rare chemicals (Milwaukee) catalog no. S60642-1. Male hybrid asparagus seeds were provided by Jersey Asparagus Farms (Pittsgrove, N.J.). Treatment solutions were made fresh each day by first dissolving NPC in a small volume of dimethyl sulfoxide (DMSO) and diluting with water so that the final concentration of DMSO was $0.5 \%$ (a 0.4 mM NPC solution appears turbid, but should not be filtered). All experiments were conducted at $25{ }^{\circ} \mathrm{C}$ in an incubator equipped with cool-white fluorescent lighting (9-90 $\left.\mu \mathrm{mol} \cdot \mathrm{m}^{-2} \cdot \mathrm{s}^{-1}\right)$. Unless otherwise noted the following protocol was used: seeds (30-40) were incubated in sterile disposable petri dishes $(100 \times 15 \mathrm{~mm})$ with two layers of Fisherbrand G8 glass fiber paper (Fisher Scientific, Springfield, N.J.) and $18 \mathrm{~mL}$ of water for at least $5 \mathrm{~d}$ in the dark. Seeds were transferred to petri dishes containing $0.4 \mathrm{~mm} \mathrm{NPC}(12 \mathrm{~mL})$ in the light only after the radicles had emerged. For stored seed all seedlings were transferred within 2 to $3 \mathrm{~d}$ (Expt. 4), but for fresh seeds (Expt. 5) $10 \mathrm{~d}$ were needed. The dishes were agitated at $100 \mathrm{rpm}$ on an orbital shaker so that the solu- 


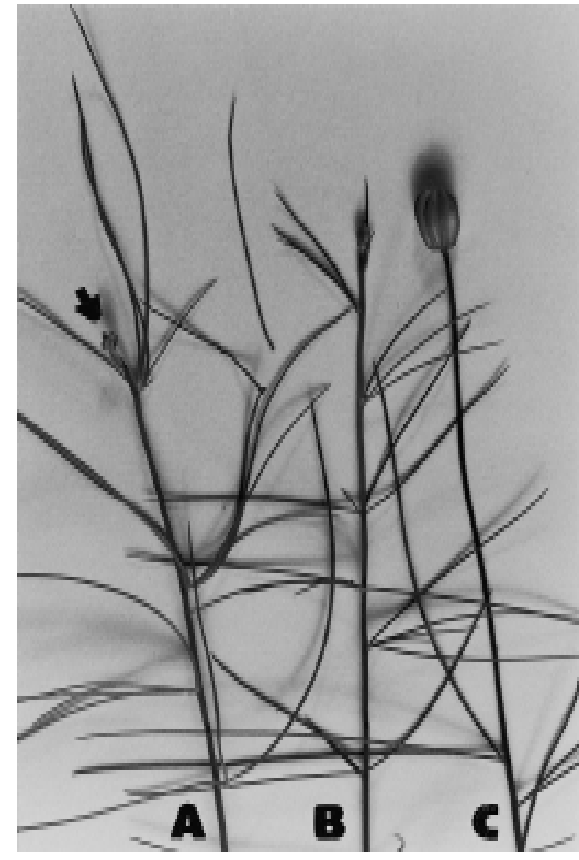

Fig. 1A-C. Effects of $n$-propyl $N$ - $(3,4-$ dichlorophenyl)carbamate (NPC) treatment on flowering of asparagus seedlings. (A) NPCtreated seedling exhibiting delayed floral development (35 d), arrow denotes flower bud; (B) nontreated seedling $(28 \mathrm{~d})$; (C) typical NPCtreated seedling $(28 \mathrm{~d})$.

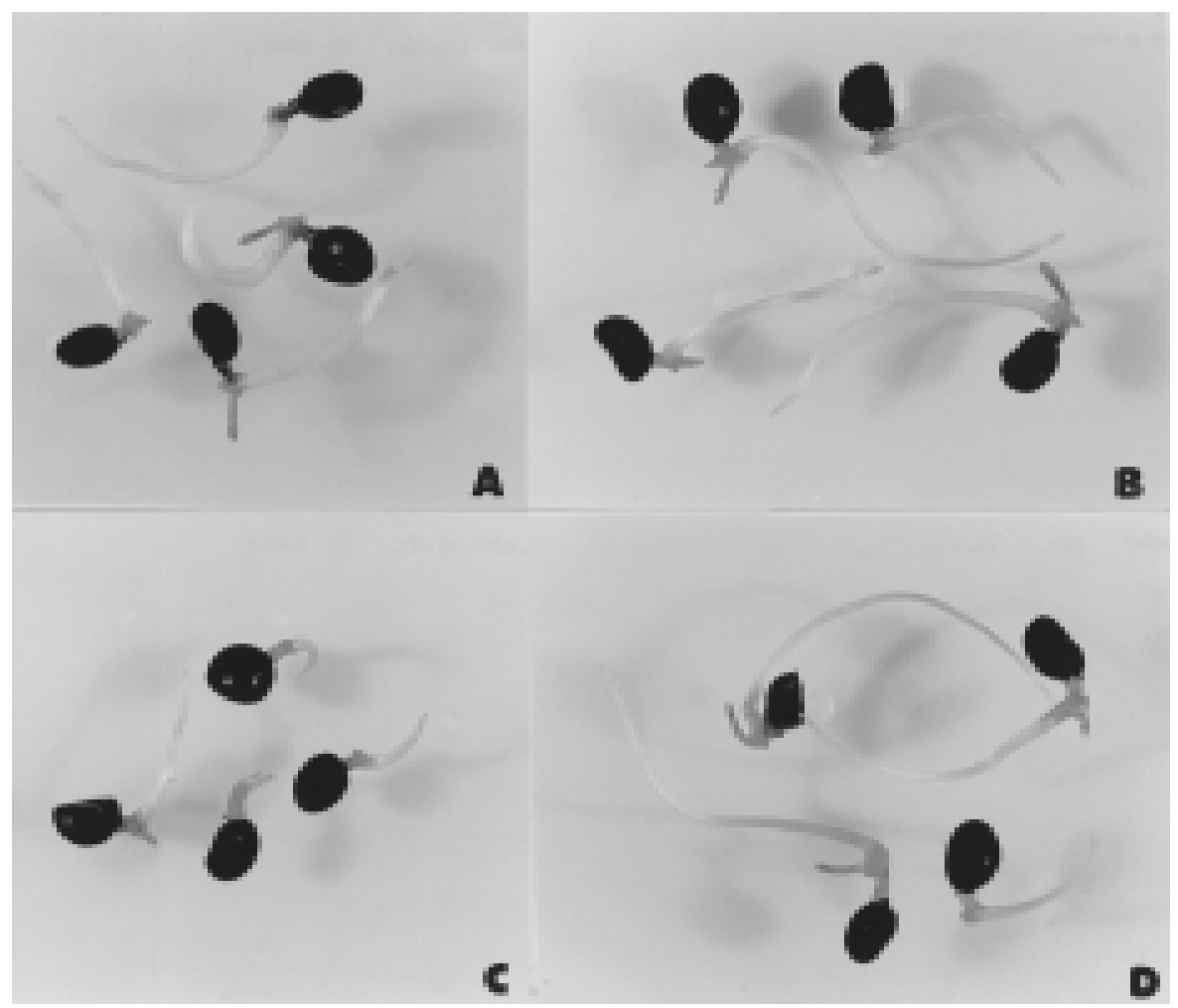

Fig. 3. Effects of NPC ( $0.4 \mathrm{~mm})$ and vigorous aeration on shoot and root elongation in seedlings of 'Jersey Knight' asparagus. All seeds were germinated in water for $5 \mathrm{~d}$ and then transferred for $5 \mathrm{~d}$ in the light in: (A) water without aeration, (B) water with aeration, (C) NPC without aeration, (D) NPC with aeration. Average root length $(\mathrm{cm} \pm$ standard error) for each treatment after $10 \mathrm{~d}$ was: (A) $1.6 \pm 0.4,(\mathbf{B})$ $2.3 \pm 0.4,(\mathbf{C}) 0.7 \pm 0.2$, (D) $2.1 \pm 0.2$.

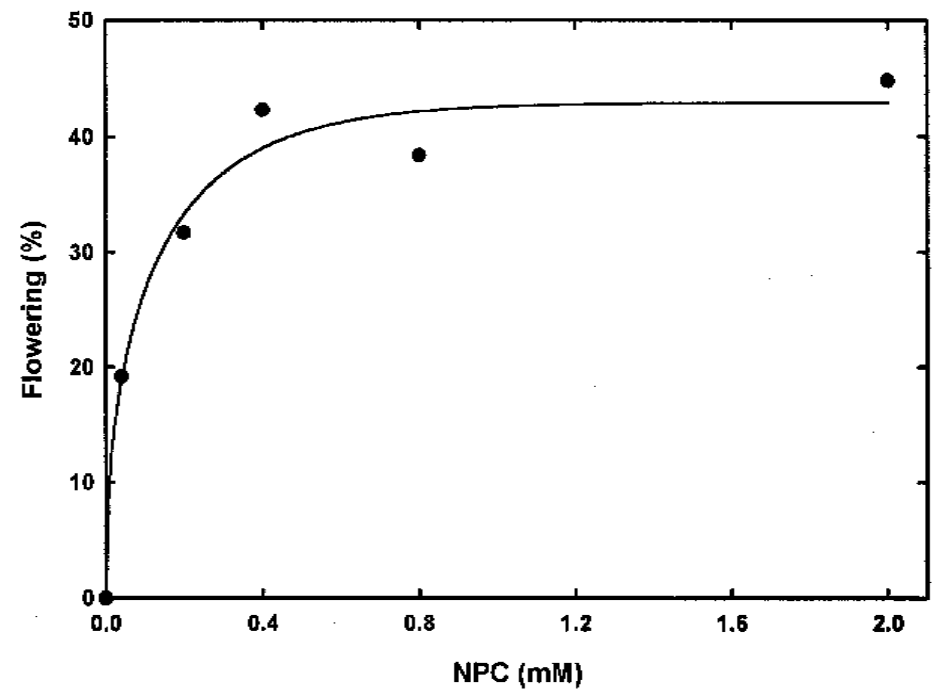

Fig. 2. Relationship between $n$-propyl $N$-(3,4-dichlorophenyl)carbamate (NPC) concentration and flowering $(\mathrm{F})$ in seedlings of asparagus 'Jersey Knight'. $\mathrm{F}=42.91\left(1-\mathrm{e}^{-4.063 \mathrm{NPC}}\right)^{0.4317}, r^{2}=0.98$. Nonaerated seeds were germinated in NPC at the start of imbibition in the light. Seedlings were evaluated once for flowers $28 \mathrm{~d}$ after sowing. Flowering percentage refers to the percentage of treated seeds that produced flowering seedlings.

tion swirled vigorously, but the seeds remained stationary within the petri dish. Seedlings were removed from treatment solutions after $5 \mathrm{~d}$, washed thoroughly with water, transplanted to flats containing vermiculite, and returned to the incubator with a light level of $\approx 90$ $\mu \mathrm{mol} \cdot \mathrm{m}^{-2} \cdot \mathrm{s}^{-1}$ in a $12-\mathrm{h}$ photoperiod. Seedlings that emerged and produced a terminal flower bud were evaluated for floral morphology 28 $\mathrm{d}$ after imbibition. Plants that appeared vegetative were allowed to develop for another 10 $\mathrm{d}$ and reevaluated. Most produced a small flower bud that could be sex-typed with the aid of a dissecting microscope.

For each experiment, there were three replicate petri dishes per treatment and each experiment was repeated at least once with similar results. The field study was not repeated.
Table 1. Effect of light and aeration on percent flowering ${ }^{z}$ of asparagus seedlings 'Jersey Knight' treated with $n$-propyl $N$-(3,4-dichlorophenyl) carbamate (NPC).

\begin{tabular}{lcc}
\hline & \multicolumn{2}{c}{ Light } \\
\cline { 2 - 3 } Aeration & + & - \\
\hline+ & $96 \mathrm{a}^{\mathrm{y}}$ & $21 \mathrm{a}$ \\
- & $55 \mathrm{~b}$ & $19 \mathrm{a}$ \\
\hline
\end{tabular}

${ }^{\mathrm{z}}$ Seeds were germinated in $0.4 \mathrm{~mm}$ NPC from the start of imbibition. Seedlings were evaluated for flowers $28 \mathrm{~d}$ after sowing. Seedlings that had not flowered by $28 \mathrm{~d}$ were reevaluated at $38 \mathrm{~d}$.

'Mean separation within columns by Fisher's protected LSD at $P \leq 0.05$. Data were transformed to $\arcsin \sqrt{ } \%$ prior to analysis.

Percent flowering was determined as the product of the percent seed germination $\times$ percent seedling emergence from vermiculite after transplanting $\times$ percent emerged seedlings that flowered. Data were analyzed using an analysis of variance for a factorial experiment and means separated with Fisher's protected least significant difference, $P \leq 0.05$. Percentage data were transformed to $\arcsin \sqrt{ } \%$, when appropriate. In some figures, standard error bars are presented. To compare sex ratios of field and lab samples, a chi square test for proportions was used (Snedecor and Cochran, 1980) and $P$-values are presented.

Several preliminary experiments are described that led to the development of the final protocol. The methods used for these experiments are as follows:

Expt. 1. Effect of NPC treatment rate on 
flowering. Seeds were germinated with NPC in the light from the start of imbibition without aeration and evaluated only once (Fig. 2).

Expt. 2. Effect of light and aeration on flowering. Seeds were germinated with NPC from the start of imbibition with or without light or aeration and evaluated twice (Table 1 and Fig. 3).

Expt. 3. Flowering in the field vs. NPC treatment. For the field experiments, seeds were harvested in December and held at $5{ }^{\circ} \mathrm{C}$ and $40 \%$ to $50 \%$ relative humidity until planting in mid-February. Seeds were first planted in peat-vermiculite mix in 72-cell trays and grown in the greenhouse at 20 to $27^{\circ} \mathrm{C}$. Seedlings were transplanted into the field in late May at a spacing of $30 \mathrm{~cm}$ in the row with 1.5 $\mathrm{m}$ between rows. Plants began flowering in late July and almost $90 \%$ of the plants had flowered by the end of October. Nonflowering plants were dug in November, potted in $15-\mathrm{cm}$ diameter containers, and grown in the greenhouse at 20 to $27{ }^{\circ} \mathrm{C}$. Almost $100 \%$ of the plants had flowered by the end of March. For the NPC treatment experiments, seeds were germinated with NPC in the light from the start of imbibition with aeration and evaluated twice (Table 2).

Expt. 4. Delayed NPC treatment. Seeds were germinated in either light or darkness, and either in the presence or absence of NPC, for $5 \mathrm{~d}$, before transfer to NPC in the light for $5 \mathrm{~d}$ with aeration (Fig. 4).

Expt. 5. Comparison between fresh and stored seeds. Fresh seeds were used within 3 months of harvest as described above and stored seed was kept under similar conditions for at least 1 year (Fig. 5).

\section{Results and Discussion}

Expt. 1. A concentration of $0.04 \mathrm{~mm}$ induced $\approx 20 \%$ of the seedlings to produce one or more precocious flowers (Fig. 2). At $0.4 \mathrm{~mm}$ the response was maximal with $40 \%$ of plants flowering. Higher concentrations of NPC up to $2.0 \mathrm{~mm}$ did not increase the percentage of plants flowering. This compound has limited solubility in water, although it is highly soluble in acetone, alcohol, and DMSO. It can be dissolved in each of these solvents and then diluted with water; however, if the concentration of organic solvent exceeds $0.5 \%(\mathrm{v} / \mathrm{v})$, asparagus seed germination is inhibited (data not shown). Moreover, even in $0.5 \%$ DMSO, NPC at concentrations $>1 \mathrm{~mm}$ often precipitated from solution. Given these constraints, $0.4 \mathrm{~mm}$ is a concentration that is high enough to induce flowering without preventing seed germination or seedling emergence.

Expt. 2. Light during the treatment phase is important for floral induction with NPC. For nonaerated treatments, only $19 \%$ of NPCtreated seedlings kept in darkness for the first $12 \mathrm{~d}$ after sowing flowered, whereas $55 \%$ of such seedlings flowered when exposed to light during this period (Table 1). With aeration, almost all of the treated seeds produced flowering seedlings. The light intensity required for flowering was minimal and the percentage
Table 2. Effects of treatment with $n$-propyl $N$-(3,4-dichlorophenyl)carbamate (NPC) during germination on sex ratios of seven male hybrid asparagus cultivars in comparison with field-grown nontreated plants.

\begin{tabular}{lccccccc}
\hline \hline & \multicolumn{2}{c}{ Field-grown plants } & & \multicolumn{2}{c}{ NPC-treated plants } & & \\
\cline { 2 - 3 } Cultivar & $\begin{array}{c}\text { No. plants } \\
\text { examined }\end{array}$ & $\begin{array}{c}\text { Females } \\
(\%)\end{array}$ & & $\begin{array}{c}\text { No. plants } \\
\text { examined }\end{array}$ & $\begin{array}{c}\text { Females } \\
(\%)\end{array}$ & Chi-square & $P$ value \\
\hline Jersey King & 428 & 4.4 & 58 & 5.2 & 0.064 & 0.996 \\
Jersey Gem & 78 & 0 & 48 & 2.1 & 1.638 & 0.651 \\
Jersey Prince & 383 & 10.4 & 59 & 6.8 & 0.766 & 0.858 \\
Jersey Knight & 68 & 0 & 50 & 0 & --- & -- \\
Jersey General & 445 & 11.9 & 43 & 9.3 & 0.258 & 0.968 \\
Jersey Giant & 476 & 13.2 & 42 & 16.7 & 0.389 & 0.942 \\
Jersey Greenwich & 441 & 14.5 & 50 & 12.0 & 0.232 & 0.972
\end{tabular}

${ }^{2}$ Seeds were germinated in NPC in the light with aeration from the start of imbibition.

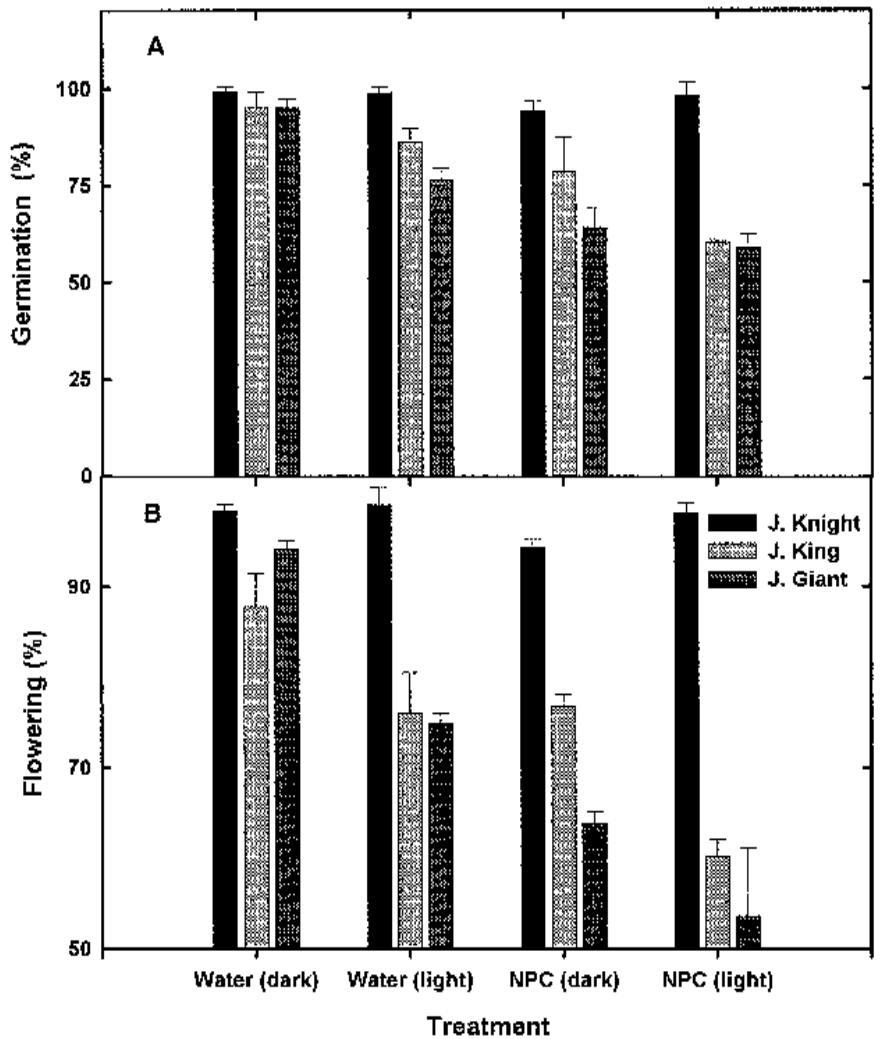

Fig. 4. Effect of delayed NPC treatment on (A) seed germination and (B) flowering in seedlings of 'Jersey Knight', 'Jersey King', and 'Jersey Giant' asparagus. All seedlings were transferred to 0.4 mM NPC in the light for $5 \mathrm{~d}$ with aeration after the initial $5 \mathrm{~d}$ treatments listed. Bars indicate standard errors. Seedlings were evaluated for flowers $28 \mathrm{~d}$ after sowing. Plants that had not flowered were reevaluated after $38 \mathrm{~d}$. Flowering percentage refers to the number of flowering seedlings as a percentage of treated seeds.

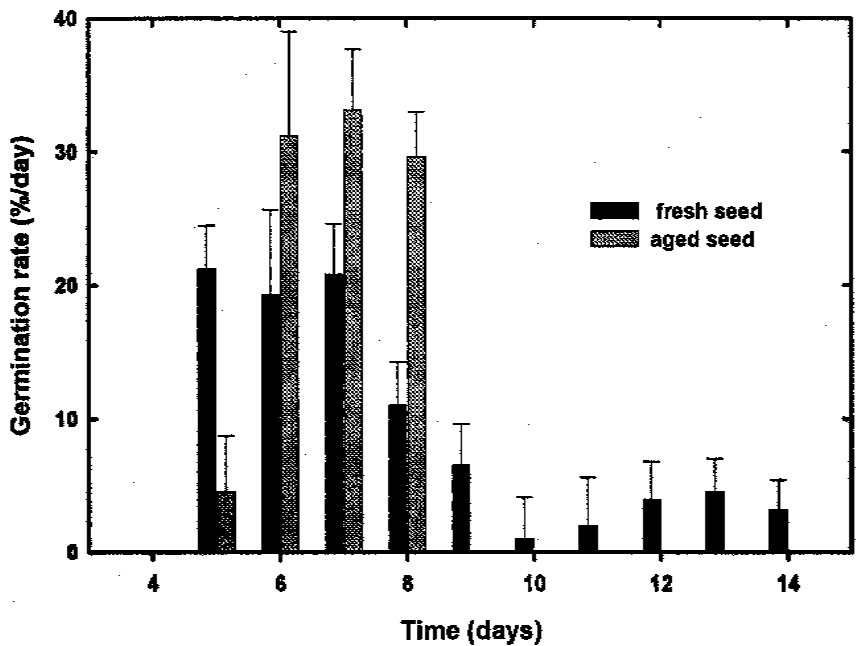

Fig. 5. A comparison of the germination rates (percent seeds with emerged radicles/day) of freshly harvested vs. 1-year-old asparagus seeds. 
of plants that flowered was similar at light intensities ranging from $9-90 \mu \mathrm{mol} \cdot \mathrm{m}^{-2} \cdot \mathrm{s}^{-1}$ (data not shown).

Root and shoot elongation was inhibited at NPC rates necessary for flower induction (Fig. 3 ). This often led to poor germination and/or emergence. Roots of treated plants appeared swollen and thickened and were often much shorter than normal. After $10 \mathrm{~d}$, the length of roots of nontreated plants was $1.6 \pm 0.4 \mathrm{~cm}$ vs $0.7 \pm 0.2 \mathrm{~cm}$ for NPC-treated plants. Aeration of seedlings during the treatment period greatly increased root and shoot elongation as well as the percentage of plants that flowered. After $10 \mathrm{~d}$ with aeration NPC-treated plants had roots $2.1 \pm 0.2 \mathrm{~cm}$, as long as roots of nontreated plants $(2.3 \pm 0.4 \mathrm{~cm})$ given aeration. The first shoot that emerged from most of the seedlings treated with NPC had a terminal flower bud, but few, if any, cladophylls along the axis (Fig. 1C). A small (2\% to $15 \%)$ percentage of plants, however, had a first shoot that appeared to be vegetative, with numerous cladophylls and scales surrounding the apical bud. About 1 week after the plants with distinct terminal floral buds had flowered, the shoot apex of the plants from this second group differentiated into a small flower that could be sex-typed using a low-power microscope (Fig. 1A). In previous work (Yanosaka et al., 1989), flowering percentages may have been underestimated if these late flowering plants were discarded.

Expt. 3. Although NPC clearly induces precocious flowering, sex ratios could differ from those of plants grown in the field. In none of the cultivars were there statistically significant differences in sex ratios between the NPC-treated seedlings that flowered precociously and seedlings grown to flowering in the field (Table 2). This relationship is important and has not been demonstrated before for the male hybrid cultivars. Although asparagus flowers are unisexual, they do contain rudimentary organs of the opposite sex type (Lazarte and Garrison, 1980), and the effect of NPC on differentiation of flower types had not been determined. These data clearly demonstrate that NPC induces precocious flowering without affecting the sex of the differentiating flower primordia.

When the NPC treatment method listed for Expt. 3 was used on the seven cultivars, an average of $71 \%$ of the treated seeds produced flowering plants. Given the nonsignificant chisquare values between NPC-treated and fieldgrown plants, there was no difference in sextype ratio between the group of treated seeds that produced flowering plants and the group that did not either germinate, emerge, or flower. This is also of considerable significance. While obtaining maximal flowering percentages is clearly desirable, the data indicate that this level $(\approx 70 \%)$ of flowering is adequate for accurate sex typing.

Expt. 4. 'Jersey Knight' germinated well in the presence of $0.4 \mathrm{~mm} \mathrm{NPC}$, and $98 \%$ of the treated seeds produced flowering seedlings (Fig. 4); however, there was considerable cultivar variation in tolerance to the growthinhibiting effects of $N$-phenylcarbamates. We therefore studied the effect on flowering of delaying NPC treatment until after germination had occurred in either light or darkness. Germination percentages for 'Jersey King' and 'Jersey Giant' were significantly higher when seeds were imbibed in water alone, than when germinated in the presence of NPC (Fig. 4A). Treating seedlings with NPC after $5 \mathrm{~d}$ in water resulted in high percentages of both germination and flowering (Fig. 4A-B). For 'Jersey King' initially imbibed on water in the dark [Fig. 4, water (dark)], 95\% of the seeds germinated and $88 \%$ of the treated seeds produced flowering seedlings. For 'Jersey Giant', $95 \%$ of the seeds germinated and $94 \%$ of the treated seeds produced flowering seedlings. This is in contrast to treating seedlings with NPC at the start of imbibition [Fig.4, NPC (dark)]. Only $78 \%$ of the 'Jersey King' seeds germinated and $77 \%$ produced flowering seedlings, and only $64 \%$ of the 'Jersey Giant' seeds germinated and $63 \%$ produced flowering seedlings. The success of the delayed NPC treatment also indicates that the critical time for flower induction probably does not begin until after radicle emergence (see also Yanosaka et al., 1991). Delaying treatment until $>2 \mathrm{~d}$ after radicle emergence, however, greatly reduced flowering (data not shown). Finally, seedlings must remain on NPC for at least $4 \mathrm{~d}$ to induce the maximal flowering response (data not shown).

Expt. 5. Freshly harvested seed did not germinate as uniformly as stored seed (Fig. 5). Greater than $90 \%$ of the stored seed germinated over a 3-d period, whereas freshly harvested seed required $10 \mathrm{~d}$. In order to maximize germination, seedling emergence, and flowering, NPC must be provided only during the stage in development when the seedling is responsive to floral induction. Only by transferring seedlings to NPC within $1 \mathrm{~d}$ of radicle emergence did we obtain a high percentage (>80\%) of flowering plants. When all of the seeds were transferred to NPC at the same time, $5 \mathrm{~d}$ after sowing, germination of some of the seeds was inhibited and they were not exposed to NPC either at the critical time or for the required length of time. As a result, only $\approx 25 \%$ of the treated seeds developed into flowering seedlings (data not shown).

Observations led to three significant improvements in the method to sex asparagus in the seedling stage. 1) Delaying NPC treatment until radicle emergence improved the percentage of seedlings that flowered. 2) Vigorous aeration of treated seedlings stimulated root and shoot growth and increased seedling emergence. 3) A second group of treated seedlings appeared to be vegetative, but exhibited delayed floral development if allowed to grow. For 'Jersey Knight', $98 \%$ of the treated seeds produced flowering seedlings using the revised treatment methods (Expt. 4; Fig. 4), vs. only $40 \%$ using the original protocol of Expt. 1 (Fig. 2). In addition, we have demonstrated that sex ratios from chemically induced seedlings accurately reflect the sex ratios found in field-grown plants.

Little is known about the mechanism of action of the $N$-phenylcarbamates and other analogs that are capable of inducing precocious flowering in asparagus. The $s$-triazines, phenylureas, and $N$-phenylcarbamates are herbicides that inhibit photosynthesis. Yanosaka et al. (1989) compared a series of $N$ phenylcarbamates for their ability to induce flowering and inhibit the Hill reaction in isolated spinach chloroplasts, but there was no correlation between these activities. The $s$ triazines and phenylureas also have anti-cytokinin activity in the soybean callus growth assay (Shimizu et al., 1990); however, benzyladenine $(4 \mathrm{~mm})$ is not able to prevent flowering in $N$-phenylcarbamate-treated plants (Yanosaka et al., 1989). Yanosaka et al. (1991) found an inverse correlation between the level of chlorogenic acid and flowering. They proposed that the inhibition of t-cinnamic acid 4-hydroxylase, a cytochrome $\mathrm{P} 450$ monooxygenase, might be the mode of action. However, a comparison of the ability of the $N$ phenyl- $N^{\prime}$-alkoxyformamidines to induce flowering and inhibit t-cinnamic acid 4-hydroxylase activity revealed no significant correlation (Kusukawa et al., 1994). Piperonyl butoxide, a broad-spectrum cytochrome P450containing enzyme inhibitor, does induce flowering in asparagus (Tanigaki et al., 1993). These enzymes use $\mathrm{O}_{2}$ as a substrate, and this may be the reason why vigorous aeration overcame the inhibitory effect of NPC on root and shoot elongation (Fig. 3). There are many cytochrome P450-containing enzymes in plants, including those involved in gibberellin synthesis and sterol metabolism. Which of these enzymes or combinations of enzymes are involved in floral induction in asparagus remains to be determined.

In conclusion, NPC can be used to accurately determine sex ratios in commercially produced male hybrid asparagus seed lots. This will save considerable time and expense since sex ratios can be obtained in 3 to 4 weeks rather than the 12 to 15 months required to grow the seedlings in the greenhouse and field. In addition, seed will no longer have to be stored until the results from field sex tests are obtained, but can now be sold as soon as NPC assays are completed. The use of NPC in asparagus breeding to rapidly assess the sex ratio of test crosses, used to confirm the identification of supermales as potential parents for male asparagus hybrids, should also be possible.

\section{Literature Cited}

Abe, T., H. Iwamura, and T. Kameya. 1990. Flower induction by triazines, ureas and carbamates in seedlings of Asparagus. Acta Hort. 271:491496.

Abe, T. and T. Kameya. 1986. Promotion of flowering formation by atrazine and diuron in seedlings of asparagus. Planta 169:289-291.

Abe, T., R. Shimizu, H. Iwamura, and T. Kameya. 1987. Flower induction by atrazine analogues in seedlings of Asparagus officinalis. Physiol. Plant. 70:228-230.

Ellison, J.H., S.A. Garrison, and J.J. Kinelski. 1990. Male asparagus hybrids: 'Jersey Gem', 'Jersey General', 'Jersey King', 'Jersey Knight', and 'Jersey Titan'. HortScience 25:816-817.

Feng, X.R. and D.J. Wolyn. 1994. Recovery of 
haploid plants from asparagus microspore culture. Can. J. Bot. 72:296-300.

Gonzalez-Castanon, M.L. 1990. Evaluation of male and female asparagus plants. Interest in obtaining male or dioecious hybrids. Acta Hort. 271:8389.

Hara, T., N. Wada, and H. Iwamura. 1992. Flower induction in asparagus seedlings by anilide and benzamide derivatives. J. Agr. Food Chem. 40:1692-1694.

Kusukawa, M., N. Wada, K. Hayakawa, and H. Iwamura. 1994. $N$-pheny- $N^{\prime}$ - alkoxyformamidines and alkanamidines as potent floweringinducing compounds in Asparagus seedlings and their effects on microsomal t-cinnamic acid 4-hydroxylase. Biosci. Biotech. Biochem. 58:2220-2223.

Lazarte, J.E. and S.A. Garrison. 1980. Sex modification in Asparagus officinalis L. J. Amer. Soc. Hort. Sci. 105:691-694.

Shimizu, R., H. Iwamura, and T. Fujita. 1990. Anticytokinin activity of N-phenyl- and Npyridylcarbamates. Z. Naturforsch. 45c:89-95. Snedecor, G.W. and W.G. Cochran. 1980. Statistical methods. 7th ed. Iowa State Univ. Press, Ames.

Tanigaki, F., A. Ishihara, K. Yoshida, T. Hara, and M. Shinozaki. 1993. Interaction of microsomal cytochrome P-450s and $N$-phenylcarbamates that induce flowering in Asparagus seedlings. $\mathrm{Z}$. Naturforsch. 48c:879-885.
Yanosaka, K., H. Iwamura, and T. Fujita. 1989. Flower induction in seedlings of Asparagus officinalis L. by $\mathrm{N}$-phenylcarbamates. Z. Naturforsch. 44c:226-232

Yanosaka, K., H. Iwamura, M. Shinozaki, and K. Yoshida. 1991. Correlation between biosynthesis of chlorogenic acid and flowering in Asparagus seedlings induced by carbamate compounds. Plant Cell Physiol. 32:447-451.

Yeo, D., T. Abe, H. Abe, A. Sakurai, K. Takio, N. Dohmae, N. Takahashi, and S. Yoshida. 1996. Partial characterization of a $17 \mathrm{kDa}$ acidic protein, EFP, induced by thiocarbamate in the early flowering phase in Asparagus seedlings. Plant Cell Physiol. 37:935-940. 